\title{
Determinants of choosing withdrawal over modern contraceptive methods in Turkey
}

\author{
Dilek Cindoglu, Ibrahim Sirkeci \& Rukiye Fusun Sirkeci
}

To cite this article: Dilek Cindoglu, Ibrahim Sirkeci \& Rukiye Fusun Sirkeci (2008) Determinants of choosing withdrawal over modern contraceptive methods in Turkey, The European Journal of Contraception \& Reproductive Health Care, 13:4, 412-421, DOI: 10.1080/13625180802255719

To link to this article: https://doi.org/10.1080/13625180802255719

曲 Published online: 06 Jul 2009.

Submit your article to this journal $ひ$

Џ Article views: 89

Citing articles: 10 View citing articles $\left[\begin{array}{c} \\ \end{array}\right.$ 


\title{
Determinants of choosing withdrawal over modern contraceptive methods in Turkey
}

\author{
Dilek Cindoglu^, Ibrahim Sirkeci ${ }^{\dagger}$ and Rukiye Fusun Sirkeci ${ }^{\star}$ \\ *Department of Political Science, Bilkent University, Ankara, Turkey, 'European Business School London, Regent's \\ College, UK, and "Department of Obstetrics and Gynaecology, Lister Hospital, Stevenage, UK
}

Objectives The determinants of the use of withdrawal in Turkey are examined using a multinomial logistic model.

Methods Data were drawn from a nation-wide population-based cross-sectional study, the Turkish Demographic Health Surveys that took place in 1998 and 2003. Detailed interviews were conducted with 8576 women aged 15-49 and analysed using SPSS.

Results Contextual, cultural and demographic characteristics define women's choice of withdrawal over modern methods. Socio-economic status, education, employment status, and past fertility behaviour are among key determinants. First-ever used contraception method has a very strong impact on later choices. Urban women, the more educated, those with better socioeconomic status, and those living in less crowded households resort less to withdrawal. Experience and empowerment positively linked to modern contraceptive use among women in Turkey.

Conclusions The use of contraceptive methods in Turkey differs greatly. Empowerment of women in terms of better socioeconomic status, better education, modern and liberal attitudes towards women and family planning seem to reduce withdrawal use as the main method of contraception. The results suggest the need for education (particularly targeting young women and couples), information and provision of modern contraceptive services particularly for disadvantaged groups.

K E Y W O R D S Coitus interruptus, Withdrawal, Women empowerment, Contraception, Turkey

\section{N T R O D U C T I O N}

Modern contraception is widely practised in certain European countries (e.g., Denmark, Germany, Italy, Spain, and Poland) whereas in some others (e.g., Italy, Spain, and Poland) one often applies a traditional method such as withdrawal or periodic abstinence ${ }^{1}$. Religion and geographic location may explain the difference. In southern Italy, for example, withdrawal was most commonly resorted to $(33.4 \%)$ whereas in Germany and Denmark it was used by only $1.4 \%$ of couples ${ }^{1}$. This South-North divide can be extended to include Turkey in the far southeast corner of Europe. Although the use of modern contraceptive methods in that country has risen since the 1980s, traditional methods, particularly withdrawal, remained salient.

Correspondence: Ibrahim Sirkeci, PhD, European Business School London, Regent's College, Inner Circle, Regent's Park, London, NW1 4NS, UK. E-mail: sirkecii@regents.ac.uk 
Patterns of contraceptive use in Turkey can be followed through the most recent three surveys conducted by the Demographic Health Surveys and the Turkish Ministry of Health (1993, 1998 and $2003)^{2,3}$. In all three studies, the proportion of couples using withdrawal was around $25 \%$. These differences between European countries also reflect age, socioeconomic status, gender roles in society, attitudes towards birth control, as well as availability and accessibility of contraceptive methods ${ }^{1,4,5}$.

Historically, various methods have been used to prevent pregnancy and to control fertility, including periodic abstinence and coitus interruptus (CI, withdrawal). More effective methods have been invented and improved and, since the 1960s, wider acceptance of contraception is supported by the legislative changes across the globe ${ }^{6}$. The risk of HIV/AIDS brought about a change in views on contraception ${ }^{7}$. However, in many countries, usage rates have yet to improve. In Turkey, about a third of women aged 15 to 49 years are still not using any contraceptive method ${ }^{3,8,9}$. The data analysed in this paper are derived from the Turkish Demographic Health Surveys conducted in 1998 and 2003 (TDHS) which collected rich information about contraceptive use and socioeconomic environment of women aged 15 to 49 years. It provided us an opportunity to investigate the determinants of withdrawal use.

Withdrawal studies around the world suggest that modernization of a society is strongly correlated with a decrease in the proportion of the population using CI as a birth control method ${ }^{10}$. Santow comments on this phenomenon with reference to the sex role differentiation $^{11}$. Wiebe, too, argues that ethnic Chinese women in Canada report that all these methods (i.e., CI, male condom and rhythm) are under male control and women have difficulties in negotiating their use with partners ${ }^{12}$. Okun found some evidence from the Jewish population of Israel supporting Santow's hypothesis $^{13}$. In Greece, Muslims with a permanent sexual relationship have recourse to CI whereas Christians use condoms ${ }^{14}$. Similar high usage rates are found in Muslim countries in the Middle East ${ }^{15,16}$.

Since the late 1970s, fertility behaviour in Turkey has changed ${ }^{17}$. Alongside decreasing birth rates, the use of contraceptive methods among married women has risen from less than $40 \%$ to over $60 \%{ }^{18}$. Nevertheless, CI has remained most commonly used for a variety of reasons ${ }^{19-22}$. Education decreases the use of withdrawal while husband's traditional attitudes have the opposite effect ${ }^{23}$. Religion was identified as a key variable determining contraceptive method and withdrawal was perceived to be a suitable modality according to religion in earlier studies in Turkey, which reported that local religious leaders favoured this 'natural and harmless' method which was also 'encouraged by the Prophet' ${ }^{24,25}$. This explains the high prevalence of withdrawal use among couples in Turkey to a certain extent.

Two other studies analysing the TDHS data suggest that the use of withdrawal is determined by the woman's age, the husband's education, withdrawal having been the first ever method used by respondents, work status, ethnicity, and region ${ }^{18,26}$. These studies are largely data-driven and descriptive. For example, Ergocmen and colleagues ${ }^{18}$ use stages which mix individual and environment levels in their four stage binary logistic regression model. Such binary models are not able to fully capture the situation where alongside CI other method choices are available to women. We propose a multinomial logistic regression model taking into account different levels of factors, namely contextual, cultural, and demographic. This fits to our perspective focusing on the social structure where women empowerment is conceptualised as the overarching single determinant, which is measured by these three groups of variables. We believe, in accordance with Santow's ${ }^{11}$ model, that it is the empowerment of women which makes a difference. However, women's empowerment in Turkey is easier said than done because of strong traditional structures, patriarchal practices including early marriages, arranged marriages, polygamy and bride price ${ }^{27}$. This is also further entrenched by low levels of educational attainment and limited participation in labour force: only $25 \%$ of all women worked in 2004, and half of this work was unpaid household labour. We have examined the factors indicating women's empowerment in three categories, namely contextual/environmental, cultural and demographic.

\section{MATERIALS AND METHODS}

The multinomial regression analysis is based on TDHS 1998 data while breakdown of contraceptive methods use by age groups is drawn from TDHS 1998 and TDHS 2003, which are part of the worldwide Demographic Health Survey (Measure DHS +) 
programme ${ }^{2,3}$. At the time of this study, TDHS 2003 data $^{3}$ was not yet made publicly available; therefore we used the previous TDHS conducted in $1998^{2}$. Currently still, only a preliminary set of the data is available (see Measure DHS + website). However, we have checked the 2003 survey report and the data that were accessible. The report states that 'these data [1993, 1998 and 2003] also indicate that the level of traditional method use remained almost unchanged' and that 'use of withdrawal remained at the same level' 3 . Therefore, we are confident that there are no serious flaws regarding the choice of data set. Nevertheless, we have yet included 2003 results in Table 1 where we summarize contraceptive method use by age groups.

TDHS 1998 was based on a nationwide representative sample of 8059 households with 8576 women of reproductive age (15 to 49 years) using a weighted multi-stage, stratified cluster sampling approach. Two main questionnaires were used to collect information: a household questionnaire and an individual questionnaire. The results of individual questionnaires were used to analyse fertility, contraception, and marriage experiences while the household data provided information on broader demographic and socio-economic characteristics of all the members of the household and general circumstances to which households are exposed. The data set used here, with the permission of Measure DHS+, combines the broader information from the household questionnaire and the individual questionnaire. In our regression analysis we included all 6152 ever-married women aged 15 to 49 years. Unlike some other studies using the data $\operatorname{set}^{18}$, we have not excluded those who are divorced, separated or widowed because sexual activity, and therefore, birth control do not necessarily cease with the end of a marriage.

Introducing three categories of variables, we aimed to cover the various factors influencing withdrawal use in Turkey. Hence, contextual factors describing the overall socio-economic environment, cultural factors, including mother languages and opinions on family planning (FP), and finally demographic characteristics are included in the model. Couple's opinions on family planning (approval of FP methods), gender of household head, duration of marriage, women's and their husbands' educational level, number of other women (aged 15 to 49) in the household, and women's current employment status are variables reflecting the level of empowerment of women.

The broader context was measured through four variables: socioeconomic status of the household, geographic region, type of place of residence (urban, rural), and number of persons per sleeping room. The socioeconomic status of the household was measured by an index constructed on a series of variables indicating the availability of a number of durable goods, and the availability and quality of some housing facilities. Households have scored between 0 and 37 with 0 being the lowest and 37 the highest level of socioeconomic status in this index. We preferred building such an index over the income variable in the data because economic disparities between different regions of Turkey may attribute different levels of comfort with the same amount of income. Income may not reflect the actual differences in socioeconomic status because of the huge variation of development levels between districts and provinces in Turkey $^{28,29}$. Another reason for not using income as the indicator of welfare would be the sheer size of undocumented economic activities ${ }^{28,29}$.

Cultural variables were the mother language of the women and of their husbands, women's religion, husbands' religion, women's and husbands' education (i.e., years spent at school), and women's and husbands' opinions on FP recorded through three variables: women approve or disapprove of FP, husbands approve or not, and whether husbands have objection on religious grounds.

Demographic characteristics including age, women's age at first marriage, duration of marriage, number of living children, availability of other women of reproductive ages in the household, and the total number of pregnancies were used as continuous variables. The gender of the household head and the first ever method of contraception the respondent used were two other categorical variables.

We have chosen to use a multinomial logistic regression model because it permits controlling categorical and continuous variables while allowing multiple categories in the dependent variable ${ }^{30}$. We also believe that it is important to analyse the withdrawal choice against other birth control methods instead of analysing it in isolation. In a simple binary logistic regression model, only CI users and modern method users need to be sampled. This means that more than one third of the sample is lost. Apparently 


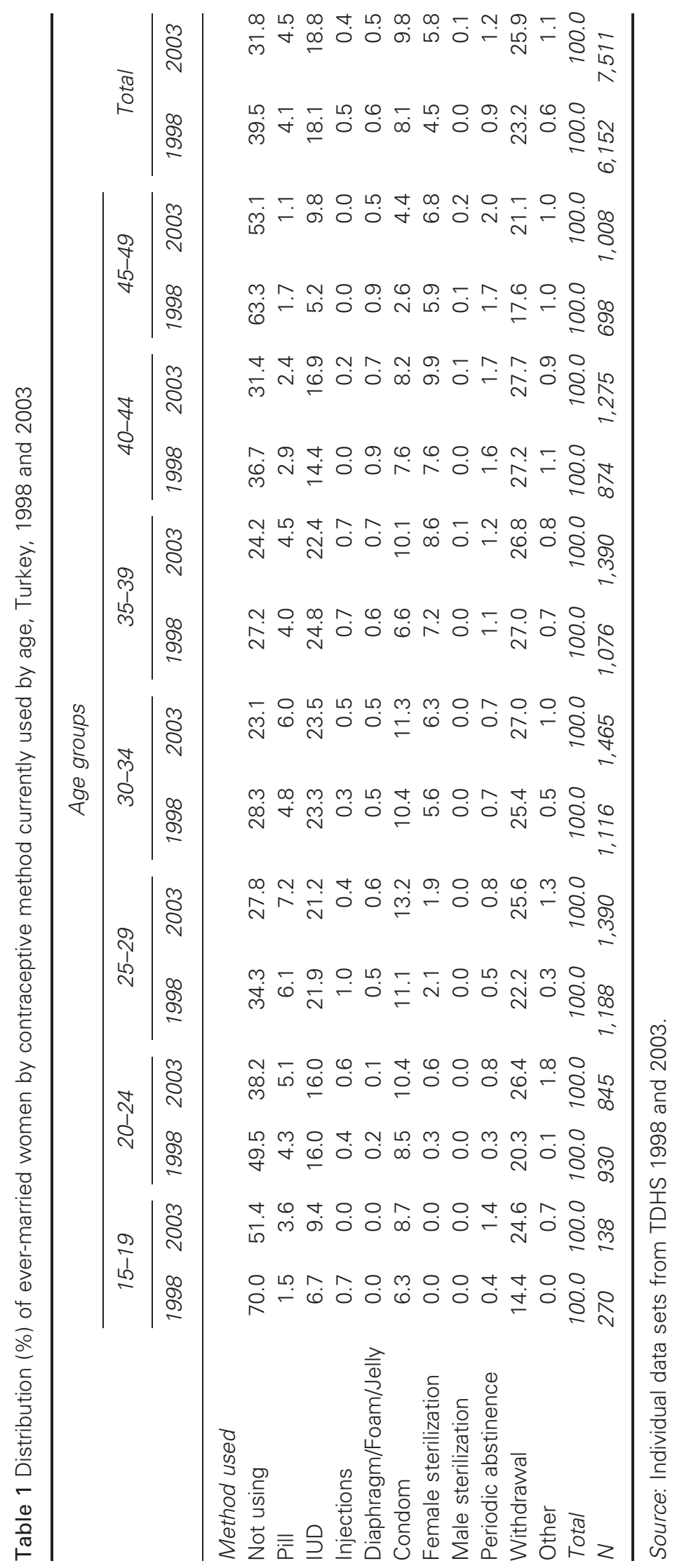


in such a model results would be biased and inaccurate in comparison to the multinomial model used here. Hence the dependent variable in our model has four categories: withdrawal, modern method, no contraception, and other traditional methods where modern method is the reference category.

\section{R E S U L T S}

Despite improving rates, modern contraceptive methods are not yet widely applied in Turkey: only about one third of ever-married women aged 15-49 resort to a modern method (Table 1). Among users of any contraceptive method, which corresponds to about $60 \%$ of ever-married women in reproductive ages, about $40 \%$ use withdrawal, the most common choice in all age groups. The second most commonly used method is the intrauterine device. The latest survey in the series confirms that that pattern is still prevalent in the country ${ }^{3}$. Table 1 displays women's birth control choices by age groups in Turkey. As can be seen, withdrawal use is higher among women aged between 30 and 44 while it is lower among younger and older women. The third commonly used method is the condom among younger women and female sterilization among the older ones.

A vast majority of women stop applying contraceptive measures due to their declining fecundity. Table 2 presents the results of multinomial logistic regression analysis examining the effects of variables on the odds of women choosing withdrawal and other traditional contraceptive methods over modern ones. Our main concern here is the choice of CI over any modern method. $R$ square (0.49) shows the strength of our multinomial logistic regression model explaining the determinants of choosing withdrawal over modern contraceptive methods. All variables have a significant effect on use of withdrawal among couples in Turkey as shown in Table 2 where all odds ratios are statistically significant $(p<0.001)$.

Wider environmental factors have also an impact on birth control choices. An improvement in socioeconomic status lessens the likelihood of withdrawal use significantly. In our model, every single unit improvement on the socioeconomic status scale (i.e., 0 to 37 ) is likely to cause a $7 \%$ reduction in use of CI. In households economically better off, couples are less inclined to use withdrawal over modern methods. Women in Southern and Northern pro- vinces are less likely to use modern methods than those living in the West of the country. In the East, traditional methods are much more common: women there are about 1.3 times more likely to use other traditional methods and about 1.5 times more likely not to apply any contraceptive measures at all. Urban dwellers use withdrawal to a lesser extent: the odds of choosing withdrawal among women residing in urban areas are reduced by about $5 \%$. The uneven distribution of wealth and different developmental levels between regions and urban and rural areas possibly explain this pattern. Regarding the wider environment, we also looked at the number of persons per sleeping room, as crowding in the household may affect use of withdrawal. Even a fractional increase in space available, sleeping rooms, significantly decreases the chances of using withdrawal. Thus we argue that women's access to better socio-economic resources empowers them towards organizing and taking decisions about their own lives, as well as on birth control choices. Better socio-economic conditions are associated with easier access to modern contraceptive methods.

The second category of variables covers cultural characteristics. Ethnic differences can be observed through mother language variables in the TDHS data. Kurdish speaking women are 1.56 times more likely to use CI over modern methods than Turkish speaking citizens. Compared to Turks, Arabic speaking women are $31 \%$ less likely to resort to withdrawal but on the other hand, they are 1.45 times more likely to apply other traditional methods. It is interesting that we should observe a $34 \%$ reduction in use of withdrawal among women married to Kurdish speaking men compared to those married to Turkish speaking men. Again, we believe that this trend is balanced by the fact that women with Kurdish speaking husbands are 2.2 times more likely to apply other traditional methods instead of modern methods and 1.2 times more likely not to use any contraception at all. Kurds and Arabs are largely residing in areas of the country where health and education services are less developed, and approaches towards FP and gender roles less liberal $^{27,31}$.

Unlike Ergocmen et al.'s claim, religious sect is a significant variable: Alevi women use withdrawal 22\% less than Sunnis and women married to Alevi men use withdrawal slightly more (odds ratio:1.061) than those married to Sunni men. Women belonging to other 
Table 2 Multinomial logistic regression showing odds ratios for characteristics predicting withdrawal use among ever-married women, Turkey, 1998

\begin{tabular}{|c|c|c|c|}
\hline & Withdrawal & Other traditional method & No contraception \\
\hline Socioeconomic status of household & 0.934 & 1.037 & 0.921 \\
\hline \multicolumn{4}{|l|}{ Region } \\
\hline West & 1.000 & 1.000 & 1.000 \\
\hline South & 1.011 & 0.510 & 1.247 \\
\hline Central & 0.822 & 0.792 & 0.948 \\
\hline North & 1.060 & 0.697 & 1.169 \\
\hline East & 0.900 & 1.294 & 1.487 \\
\hline \multicolumn{4}{|l|}{ Type of place of residence } \\
\hline Urban & 0.956 & 0.971 & 0.842 \\
\hline Rural & 1.000 & 1.000 & 1.000 \\
\hline Number of persons per sleeping rooms & 0.960 & 0.781 & 0.957 \\
\hline \multicolumn{4}{|l|}{ Mother language of women } \\
\hline Turkish & 1.000 & 1.000 & 1.000 \\
\hline Kurdish & 1.569 & 1.695 & 1.370 \\
\hline Arabic & 0.698 & 1.454 & 0.678 \\
\hline Other & 0.698 & 0.218 & 1.217 \\
\hline \multicolumn{4}{|l|}{ Mother language of husbands } \\
\hline Turkish & 1.000 & 1.000 & 1.000 \\
\hline Kurdish & 0.661 & 2.233 & 1.204 \\
\hline Arabic & 1.818 & 11.977 & 2.675 \\
\hline Other & 2.195 & 42.292 & 1.244 \\
\hline \multicolumn{4}{|l|}{ Women's religion } \\
\hline Sunni & 1.000 & 1.000 & 1.000 \\
\hline Alevi & 0.785 & 0.088 & 0.399 \\
\hline Other Muslim & 1.256 & 1.855 & 1.065 \\
\hline Others & 1.175 & 0.239 & 0.991 \\
\hline \multicolumn{4}{|l|}{ Husbands' religion } \\
\hline Sunni & 1.000 & 1.000 & 1.000 \\
\hline Alevi & 1.061 & 12.838 & 2.868 \\
\hline Other Muslim & 0.773 & 0.713 & 0.917 \\
\hline Others & 0.811 & $0.999 *$ & 0.644 \\
\hline Women's education (years spent in school) & 0.976 & 1.108 & 0.998 \\
\hline Husbands' education (years spent in school) & 1.002 & 1.039 & 0.990 \\
\hline \multicolumn{4}{|l|}{ Husbands' opinion on family planning } \\
\hline Approve & 0.596 & 0.311 & 0.579 \\
\hline Disapprove & 1.000 & 1.000 & 1.000 \\
\hline Don't know & 0.989 & 0.562 & 0.913 \\
\hline \multicolumn{4}{|l|}{ Women's opinion on family planning } \\
\hline Approve & 0.720 & ** & 0.599 \\
\hline Disapprove & 1.000 & 1.000 & 1.000 \\
\hline Don't know & 0.930 & $0.984^{*}$ & 0.618 \\
\hline \multicolumn{4}{|l|}{ Husbands object to family planning } \\
\hline Yes & 0.825 & 0.875 & 1.022 \\
\hline Some methods against religion & 1.144 & 0.347 & 1.025 \\
\hline No & 1.000 & 1.000 & 1.000 \\
\hline Don't know & 0.955 & 1.170 & 1.351 \\
\hline
\end{tabular}

(continued) 
Table 2 (Continued)

\begin{tabular}{|c|c|c|c|}
\hline & Withdrawal & Other traditional method & No contraception \\
\hline \multicolumn{4}{|l|}{ Women currently working } \\
\hline Yes & 0.928 & 0.618 & 1.149 \\
\hline No & 1.000 & 1.000 & 1.000 \\
\hline Age of women & 0.895 & 1.351 & 1.072 \\
\hline Age of husbands & 0.995 & 1.009 & 0.994 \\
\hline Women's age at first marriage & 1.133 & 0.807 & 0.934 \\
\hline Duration of marriage & 1.166 & 0.826 & 0.999 \\
\hline Number of living children & 0.876 & 0.519 & 0.644 \\
\hline Number of eligible women & 1.080 & 1.502 & 1.187 \\
\hline \multicolumn{4}{|l|}{ Sex of household head } \\
\hline Male & 1.023 & ** & 0.530 \\
\hline Female & 1.000 & 1.000 & 1.000 \\
\hline Total number of pregnancies & 0.995 & 1.208 & 1.073 \\
\hline \multicolumn{4}{|l|}{ First method women used } \\
\hline Modern method & 1.000 & 1.000 & 1.000 \\
\hline Withdrawal & 5.413 & 0.609 & 1.850 \\
\hline Other traditional method & 0.934 & 0.000 & 3.059 \\
\hline Never used & $1.652^{*}$ & $5.374^{*}$ & $* *$ \\
\hline$R$ square & .49 & & \\
\hline Df & 41 & & \\
\hline
\end{tabular}

*Differences are not significant; otherwise all significant at: $p<0.001$.

**Empty cells.

Reference categories are italicized.

Source: TDHS 1998 individual data set.

Muslim sects or other religions are more likely to use CI than Sunni women. This can be attributed to the more liberal and open-minded attitudes of Alevis ${ }^{32}$.

Among cultural variables, opinions of men and women on FP and education are analysed. For women, every single year in education means a statistically significant reduction in use of withdrawal and an increase in use of all forms of modern methods of contraception. Education does not have the same straight effect on men: every additional year in education causes a very small but statistically significant increase in odds of using CI but, at the same time, education reduces the likelihood of sex without contraception for men. The husband's favourable opinion about FP is a key variable in reducing the use of withdrawal and other traditional methods as well as increasing that of modern methods of contraception. When the husband approves FP, the odds of choosing CI over modern methods are reduced by $41 \%$. Their odds of not using any contraception are similarly halved. Women's approval of FP is associated with a $28 \%$ reduction in the odds of applying withdrawal.
Women are 1.4 times more likely to use withdrawal when their husbands think that some methods are against religion compared to other women whose husbands do not object FP.

Demographic factors, reproductive behaviour, and earlier contraceptive practices significantly influence women's choice of current method of contraception. Women currently working are less likely to use withdrawal or another traditional method but are 1.15 times more likely to avoid every contraceptive measure. Women currently not working are 1.08 times more likely to apply withdrawal and 1.62 times more likely to opt for another traditional method. The effect employment exerts can be linked to the women empowerment hypothesis according to which it is assumed that employed women take more control of their sexuality and therefore prefer modern methods ${ }^{33}$.

Age is also a statistically significant predictor of CI use. As women and men age, their likelihood of choosing withdrawal over modern methods are decreased significantly: each added year of age for women leads to a reduction by about $11 \%$ in the odds 
of using withdrawal. However, women, as they age, seem to turn to other traditional methods, too: every single year added increases the likelihood of choosing other traditional methods 1.35 times. Older women are less likely to apply CI than younger ones. Women's age at first marriage and the duration of marriage also make difference. Women who married when older are more likely to resort to CI than those who married when they were young: every single year added to women's age at first marriage increases the chances of withdrawal use 1.13 times. Likewise, as the duration of marriage increases, so does withdrawal use: odds are up 1.16 times for every additional year women stay married. These patterns can be related to experience and/or acquaintance with the method.

Fertility and birth history are important predictors of the tendency to use withdrawal. The number of pregnancies and the number of living children both are negatively correlated. A greater parity is associated with a lesser use of CI: the odds are reduced by half a percent per additional pregnancy. Very much correlated to the number of pregnancies, but a stronger determinant is the number of living children: every additional living child leads to a $12 \%$ reduction in use of withdrawal and a $48 \%$ reduction in use of any other traditional method. Having more children promotes the use of contraception; the odds of avoiding contraception are reduced by $36 \%$ with each additional child. The gender of the household head (as identified by respondents in 'listing the members in the household starting with the head of the household') ${ }^{2}$ also has a statistically significant effect on the contraceptive choice: women in male-headed households are 1.02 times more likely to apply CI than their female-headed neighbours. While $29 \%$ of women living in a male-headed household use withdrawal, only $13 \%$ do so in female-headed households. Hence, when the head of household is a woman, withdrawal use is less likely.

The single most important influence is the type of first contraceptive method used by women. If it was withdrawal, their likelihood of opting for that method instead of modern ones is 5.4 times higher.

\section{I S C U S S I O N}

Contraceptive use in Turkey has not drastically changed in the last two decades; withdrawal remains the most common method ${ }^{3}$. About one third of women apply no contraceptive measures and 38\% of those who do currently use CI. This is not surprising because in a European comparative study, withdrawal was reported to be the method most used $(33 \%)^{1}$.

Our research suggests that empowerment of women reduces use of withdrawal. Women living in urban settings have access to further education, have their own income and thus, have a greater say in their sex lives and their choice of contraceptive method than women in rural settings, with less education and income. Also experience (e.g., age, marriage duration, pregnancies, raising children) and having a female household head increase the likelihood of using a modern method instead of CI. The latter is not popular among women who are more educated, living in the western and urban parts of the country, who have less traditional ethnic (e.g., Turks) and religious backgrounds (e.g., Alevis).

Couples knowledgeable about and approving contraception are less likely to resort to CI. Their education with regard to modern FP methods would reduce the chances of their choosing withdrawal. Our study indicates the need for information programmes and for modern contraceptive services targeting particular social groups and regions in Turkey. Health services and professionals should take a central role in promoting knowledge and accessibility of modern contraceptive methods, particularly targeting young women as the first-method-used powerfully determines later preferences.

The factors affecting use of withdrawal over modern methods are complex and one should take into account people who prefer other traditional methods and those not applying any contraceptive measures. Compared to binary logistic regression, multinomial models are more capable of reflecting this complexity as they enable to distinguish effects of variables at different levels such as geographical regions or households. One step further would be the application of hierarchical models, multilevel models using specialist software such as MLwiN.

Declaration of interest: The authors report no conflicts of interest. The authors alone are responsible for the content and writing of the paper. No financial support was received.

Author names are listed in alphabetical order. 
R E F E R E N C E S

1. Spinelli A, Talamanca IF, Lauria L. Patterns of contraceptive use in 5 European countries. Am J Public Health 2000;90:1403-8.

2. Hacettepe University Institute of Population Studies. Turkish Demographic Health Survey 1998. Ankara, Turkey: Hacettepe University Institute of Population Studies, 1999.

3. Hacettepe University Institute of Population Studies. Turkish Demographic Health Survey 2003. Ankara, Turkey: Hacettepe University Institute of Population Studies, 2004.

4. Leridon H. Fertility and contraception in 12 developed countries. Fam Plann Perspect 1981;3:93-102.

5. Shah I. Fertility and contraception in Europe: The case of low fertility in Southern Europe. Eur J Contracept Reprod Health Care 1997;2:53-61.

6. Rogow D, Horowithz S. Withdrawal: A review of the literature and an agenda for research. Stud Fam Plann 1995;26:140-53.

7. McMahon S, Hansen L, Mann J, et al. Contraception. BMC Women's Health 2004;4:S25. Available at http:// www.biomedcentral.com/1472-6874/4/S1/S25.

8. Angin Z, Shorter FC. Negotiating reproduction and gender during the fertility decline in Turkey. Soc Sci Med 1988;47:555-64.

9. Aytekin NT, Pala K, Irgil E, Aytekin H. Family planning choices and same characteristics of coitus interruptus users in Gemlik, Turkey. Women's Health Issues 2001;11:442-7.

10. Harvey SM, Scrimshaw SCM. Coitus-dependent contraceptives; factors associated with effective use. J Sex Res 1988;25:364-79.

11. Santow G. Coitus interruptus in the twentieth century. Population Devel Rev 1993;19:767-92.

12. Wiebe ER, Janssen PA, Henderson A, Fung I. Ethnic Chinese women's perceptions about condoms, withdrawal and rhythm methods of birth control. Contraception 2004;69:493-6.

13. Okun BS. Family planning in the Jewish population of Israel: Correlates of withdrawal use. Stud Fam Plann 1997;28:215-27.

14. Galazios G, Emin M, Koutlaki N, et al. Differentiation in contraceptive behaviour of the female population in Thrace, Greece. Eur J Contracept Reprod Health Care 2001;6:78-86.

15. Ghazal-Aswad S, Zaib-un Nisa S, Rizk DEE, et al. A study on the knowledge and practice of contraception among men in the United Arab Emirates. J Fam Plann Reprod Health Care 2002;28:196200.
16. Myntti C, Ballan A, Dewachi O, et al. Challenging the stereotypes: Men, withdrawal, and reproductive health in Lebanon. Contraception 2002;65:165-70.

17. Kulczycki, A. The determinants of withdrawal use in Turkey: A husband's imposition or a woman's choice. Soc Sci Med 2004;59:1019-33.

18. Ergocmen BA, Koc I, Senlet P, et al. A closer look at traditional contraceptive use in Turkey. Eur J Contracept Reprod Health Care 2004;9:221-44.

19. Goldberg HI, Toros A. The use of traditional methods of contraception among Turkish couples. Stud Fam Plann 1994;25:122-8.

20. Koc I. Determinants of contraceptive use and method choice in Turkey. J Biosoc Sci 2000;32:329-42.

21. Bulut A, Filippi V, Marshall T, et al. Contraceptive choice and reproductive morbidity in Istanbul. Stud Fam Plann 1997;28:35-43.

22. Yurdakul M, Vural G. Reasons for using traditional methods and role of nurses in family planning. Contraception 2002;65:347-50.

23. Vural B, Vural F, Diker J, Yucesoy I. Factors affecting contraceptive use and behavior in Kocaeli, Turkey. $A d v$ Contracept 1999;15:325-36.

24. Cebeci SD, Erbaydar T, Kalaca T, et al. Resistance against contraception or medical contraceptive methods; a qualitative study on women and men in Istanbul. Eur J Contracept Reprod Health Care 2004;9:94101.

25. Ozturk A, Guzel H, Gun I, Osturk Y. Opinions of imams about family planning and their use of methods in Kayseri. Eur J Contracept Reprod Health Care 2002;7: 144-9.

26. Alpu O, Fidan H. On the use of contraceptive methods among married women in Turkey. Eur J Contracept Reprod Health Care 2006;11:228-36.

27. Ilkkaracan P, and Women for Women's Human Rights. Exploring the context of women's sexuality in eastern Turkey. Reprod Health Matters 1998;6:66-75.

28. Dincer B, Ozaslan M, Kavasoglu T. Illerin ve Bölgelerin Sosyo-ekonomik Gelişmişlik Stralaması Araştırması. Ankara: DPT (Turkish State Planning Organisation) Bolgesel Gelisme ve Yapisal Uyum Genel Mudurlugu, 2003.

29. DPT, Turkish State Planning Organisation. Kayitdisi Ekonomi Ozel Ihtisas Komisyonu Raporu. Ankara: DPT, 2001.

30. Judd CM, McClelland GH. Data analysis: A modelcomparison approach. New York: Harcourt Brace Jovanovich, 1989. 
31. Sirkeci I. The environment of insecurity in Turkey and the emigration of Turkish Kurds to Germany. New York: Edwin Mellen Press, 2006.

32. Vorhoff K. The past in the future: Discourses on the Alevis in contemporary Turkey, In Jongerden JJ and
White PJ, eds. Turkey's Alevi enigma: A comprehensive overview. Leiden: E.J. Brill, 2003:93-109.

33. Ozbay F. The impact of education on women in rural and urban Turkey, In Abadan-Unat N, ed. Women in Turkish Society. Leiden: E.J. Brill, 1981:160-80. 